\title{
An Unusual Location of Fibrous Hamartoma of Infancy in the Eyelid
}

\author{
Ofira Zloto $^{a, d}$ Sarit Aviel-Ronen ${ }^{b, c}$ Mordechai Rosner ${ }^{a, d}$ \\ ${ }^{a}$ Goldschleger Eye Institute, ${ }^{b}$ Department of Pathology, and ${ }^{\mathrm{C} T a l p i o t ~ M e d i c a l ~ L e a d e r s h i p ~ P r o g r a m, ~}$ \\ Sheba Medical Center, Tel Hashomer, and d Sackler Faculty of Medicine, Tel-Aviv University, Tel-Aviv, Israel
}

\section{Key Words}

Fibrous hamartoma of infancy · Eyelid lesions · Differential diagnosis $\cdot$ Histological examination

\begin{abstract}
Aim: To describe the clinical, imaging, and histopathological features of fibrous hamartoma of infancy (FHI) in the eyelid, a rare differential diagnosis for eyelid lesions. Methods: We describe the case of a 7-month-old patient with a $\mathrm{FHI}$ in the eyelid that was diagnosed after surgical removal. The unique histopathological appearance of the triphasic histologic components provided the diagnosis. Conclusions: $\mathrm{FHI}$ is included in the long list of differential diagnosis for eyelid lesions in infancy. Therefore, it is important for the ophthalmologists to be familiar with this entity in order to avoid misdiagnosis of other fibromatosis and malignant tumor as well as unnecessary aggressive treatment.
\end{abstract}

(c) 2016 S. Karger AG, Basel

\section{Introduction}

Fibrous hamartoma of infancy (FHI) is a rare, benign, fibroproliferative lesion that develops during the first 2 years of life, and up to $25 \%$ of cases are discovered

\section{KARGER}

(c) 2016 S. Karger AG, Basel

E-Mail karger@karger.com

www.karger.com/oop at birth $[1,2]$. It presents as a solitary, asymptomatic mass-like lesion located in the subcutaneous layer or the reticular dermis, and it is poorly demarcated from the adjacent soft tissue [3]. The clinical and radiologic features of this lesion are nonspecific and can mimic other soft tissue lesions. Since the initial description of FHI in 1956 by Reye [4], the diagnosis is made by histological examination. This tumor has been recognized by its classic triphasic histologic components of mature fibroblastic/myofibroblastic tissue, immature mesenchymal tissue, and mature adipose tissue [4]. The lesion may be progressive with varying paces (from slow to rapid), and the preferred treatment is surgical excision [5]. However, complete resection is often neither feasible nor needed because of cosmetic and/or functional implications. Although local recurrence may occur after incomplete excision [1], the prognosis remains excellent [6].

The usual anatomic locations of FHI include the upper extremities, axilla, and upper back [5]. Although it has been mentioned few times in the differential diagnosis for eyelid lesions in infancy [7-9], to the best of our knowledge, there are only two earlier case reports of FHI in the eyelid $[6,10]$. Here, we present the clinical, imaging, and histopathological features of FHI to make ophthalmologists more familiar with this rare entity. 

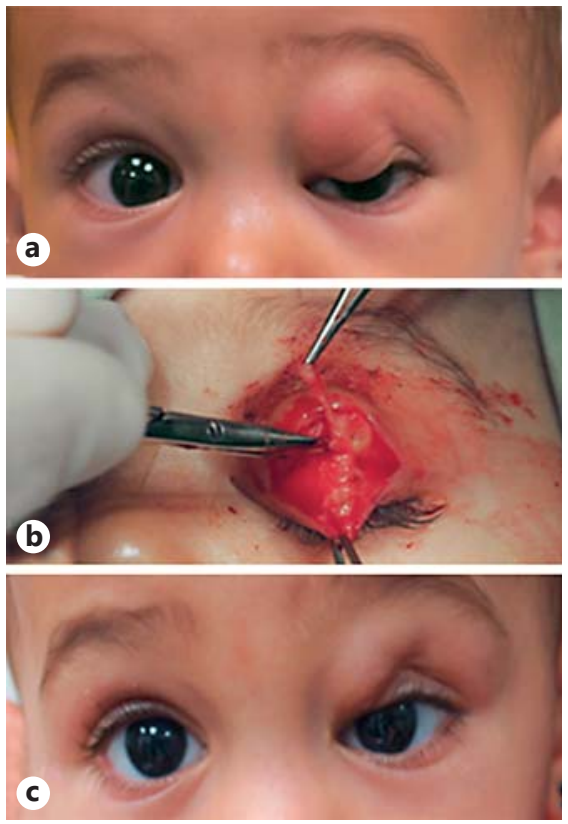

Fig. 1. Clinical appearance of FHI. a Clinical appearance of the solid lesion of the eyelid prior to surgery. $\mathbf{b}$ Image of the invasive lesion with no obvious borders during surgery. c Clinical appearance of the eyelid 2 months after surgery. It looks like there are still remnants of the lesion.

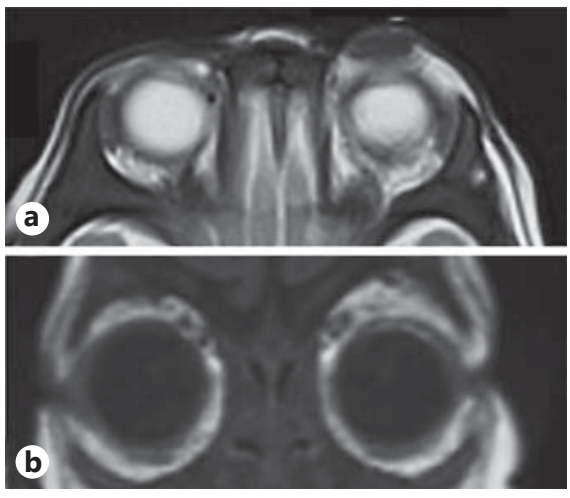

Fig. 2. Imaging of FHI. a T2-axial section: a well-marginated lesion in the superior left bony orbit is shown. The lesion was hyperintense on T2-weighted images. b A T2-coronal section is shown.

\section{Case Report}

A 7-month-old, healthy, female baby was examined by the pediatric ophthalmologist due to a left upper eyelid lesion that appeared at birth and had been growing since then. In order to prevent amblyopia, closure of the right eye for a few hours per day was recommended, and she was referred to the oculoplastic clinic at our institution for consultation and treatment.

Fibrous Hamartoma of Infancy in the Eyelid

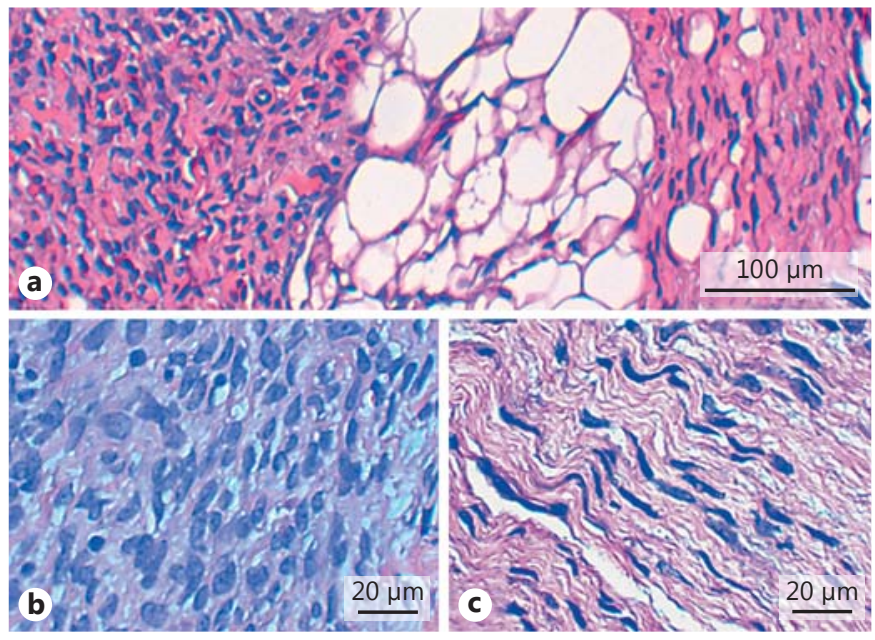

Fig. 3. Histopathological appearance of hematoxylin and eosin staining of FHI. a Classic triphasic histologic components of mature fibroblastic/myofibroblastic tissue, immature mesenchymal tissue, and mature adipose tissue. Scale bar $=100 \mu \mathrm{m}$. b Immature mesenchymal tissue. Scale bar $=20 \mu \mathrm{m}$. c Mature fibroblastic tissue. Scale bar $=20 \mu \mathrm{m}$.

On examination, the left upper eyelid lesion was solid and mobile with rubber consistency (fig. 1a). A mechanical ptosis was observed. The rest of the ophthalmic examination was normal. Magnetic resonance imaging of the orbits demonstrated a well-marginated, ovoid, osteolytic mass in the superior left bony orbit. The mass was isointense relative to the brain parenchyma on T1weighted images and hyperintense to the brain parenchyma on T2-weighted images. After administration of gadolinium contrast, the mass demonstrated marked homogeneous enhancement (fig. 2). The differential diagnosis after imaging and clinical evaluation included the following etiologies: Langerhans cell histiocytosis, fibrous dysplasia, juvenile ossifying fibroma, infantile fibrosarcoma, neuroblastoma, and primitive neuroectodermal tumor. Excision of the lesion was recommended.

During surgery, a solid, infiltrative lesion, harder than normal tissue, with no obvious borders was identified (fig. 1b) and excised. Since the lesion was infiltrative, with no clear borders, frozen sections were performed. Fibrous tissue with bland spindle cells was histologically recognized, and the surgical margins were found to be free of lesion.

After fixation and embedding in paraffin, the hematoxylin and eosin-stained sections disclosed an 'organoid' growth pattern of fascicles of mature fibroblastic tissue, with collagen deposition, hypercellular islands of round to spindle cells set within slightly myxoid stroma, and mature adipose tissue (fig. $3 \mathrm{a}-\mathrm{c}$ ).

The spindle cells in the hypercellular islands had bland nuclei and showed no mitotic activity. On immunostains, CD34 stained positively both for the fibroblastic fascicles and the hypercellular areas, Bcl-2 was positive only in the hypercellular areas, and the stains for $\beta$-catenin, S100, CD68, and MNF116 were negative. Based on the morphological features and the results of the immunohistochemical stains, the diagnosis of FHI was made. 
Today, the patient is still in follow-up in the oculoplastic clinic. The mechanical ptosis is less prominent, but there is still swelling in the nasal part of the eyelid, probably from remnants of the lesion for which future surgery is planned (fig. 1c).

\section{Discussion}

In this case report, the clinical, imaging, and histopathological features of FHI located in the eyelid are described. FHI is a rare tumor and location in the eyelid is unusual.

The clinical and radiologic features of FHI are similar to other tumors. Therefore, the definite diagnosis is made only by histopathological examination. The histopathological appearance of the triphasic histologic components of mature fibroblastic tissue, immature mesenchymal tissue, and mature adipose tissue [5] is unique to this tumor, which led to the diagnosis in our case.

FHI is included in the long list of differential diagnosis for eyelid lesions in infancy [8]. This differential diagno- sis includes a variety of reactive lesions and benign and malignant neoplasms: juvenile hyaline fibromatosis, lymphoma, neuroblastoma, infantile myofibroma, leiomyoma, fibrous dysplasia, nonossifying fibroma, dermoid cyst, and more. Therefore, it is important for the ophthalmologists and the pathologists to be familiar with this entity in order to avoid misdiagnosis of other fibromatosis and malignant tumor that may result in unnecessary aggressive treatment.

\section{Statement of Ethics}

The patient's parents agreed to the publication of the clinical photographs.

\section{Disclosure Statement}

The authors have no potential conflicts of interest to disclose.

\section{References}

1 Saab ST, McClain CM, Coffin CM: Fibrous hamartoma of infancy: a clinicopathologic analysis of 60 cases. Am J Surg Pathol 2014;38: 394-401.

2 Dickey GE, Sotelo-Avila C: Fibrous hamartoma of infancy: current review. Pediatr Dev Pathol 1999;2:236-243.

3 Scott DM, Pena JR, Omura EF: Fibrous hamartoma of infancy. J Am Acad Dermatol 1999; 41:857-859.
4 Reye RD: A consideration of certain subdermal fibromatous tumours of infancy. J Pathol Bacteriol 1956;72:149-154.

5 Carretto E, Dall'Igna P, Alaggio R, et al: Fibrous hamartoma of infancy: an Italian multiinstitutional experience. J Am Acad Dermatol 2006;54:800-803.

6 Amer S: Fibrous hamartoma of infancy. J Coll Physicians Surg Pak 2006;16:381-382.

7 Sykora KW, Weiss RA, Ellsworth RM, et al: Ophthalmic neoplasms in infancy and childhood. Pediatrician 1990;17:163-172.
8 Mynatt CJ, Feldman KA, Thompson LD: Orbital infantile myofibroma: a case report and clinicopathologic review of 24 cases from the literature. Head Neck Pathol 2011;5:205-215.

9 Trivedi D, Lee SY, Brundler MA, et al: Fibrous tumor of the superior oblique tendon in Proteus syndrome. J AAPOS 2013;17:420-422.

10 Bradfield YS, Kulkarni A, Potter HD, et al: Eyelid fibrous hamartoma with conjunctival angioma in an infant. Arch Ophthalmol 2007; $125: 843-845$ 